\title{
DA PROTEÇÃO DOS DIREITOS FUNDAMENTAIS POR MEIO DA GARANTIA DA LIBERDADE DE INFORMAÇÃO ${ }^{1}$
}

\author{
HEINRICH SCHOLLER ${ }^{2}$ \\ NING-HSIU LEE ${ }^{3}$
}

\begin{abstract}
RESUMO: Constituições e documentos internacionais protegem o direito à informação. A lei alemã sobre a matéria parece indicar que a garantia da liberdade de informação contém uma garantia de defesa e uma garantia de prestação pelo Estado. Escândalos envolvendo contaminação de alimentos exigem modificações na legislação sobre informações. A proposta de alteração legislativa na Alemanha, ainda que seja positiva em face da situação atual, ela deveria ser a rigor uma lei mais abrangente de informação ao cidadão. Há na opinião pública uma clara constatação da insuficiência das informações disponibilizadas atualmente.

PALAVRAS-CHAVE: Direitos Fundamentais; Direito à Informação; Direito do Consumidor; Transparência; Acesso à Informação.
\end{abstract}

\begin{abstract}
Constitutions and International Documents protect the right to information. German law on the subject seems to indicate that the freedom of information guarantee contains a defense/negative liberty dimension and a positive dimension requiring a state performance. Scandals involving food contamination demand changes in legislation regarding product information. The proposed legislation amendment in Germany, though it is encouraging in light of the present situation, should actually be a broader statute on information to citizens. Public opinion clearly finds the information currently made available to be insufficient.

KEYWORDS: Fundamental Rights; Right to Information; Consumer Rights; Transparency; Access to Information.

SUMÁRIO: I Informações Gerais sobre o Direito Fundamental à Informação; II Novos Casos de Conflito - O Escândalo da Dioxina; III Fontes de Acesso Geral; 1 Informação ao Público em Geral; 2 Instrução Livre e Direta; IV A Liberdade de Informação em Conflito como uma Observação Final; Referências.
\end{abstract}

\footnotetext{
Artigo recebido em 27.01.2012. Artigo aceito para publicação em 12.03.2012 mediante convite. ${ }^{1}$ Tradução do original em alemão por Marcos Augusto Maliska. marcosmaliska@yahoo.com.br

2 Professor Catedrático de Direito Constitucional, Administrativo e Filosofia do Direito da Universidade de Munique, Alemanha. scholler@jura.uni-muenchen.de

${ }^{3}$ Doutora em Direito pela Universidade de Munique, Alemanha.
} 


\section{INFORMAÇÕES GERAIS SOBRE O DIREITO FUNDAMENTAL À INFORMAÇÃO}

Muitas constituições e garantias jusfundamentais internacionais, incluindo a Lei Fundamental alemã no art. $5^{\circ}$, parte I, protegem, sob a garantia das liberdades de comunicação, o direito à informação. No entanto, permanece em aberto a resposta à questão se a garantia dos direitos humanos pertence ao status negativo, ou seja, ao status de defesa, o qual, com certeza, integra o direito fundamental precedente da liberdade de opinião e o direito fundamental posterior da liberdade de imprensa, ou se ela está vinculada ao status positivo, isto é, à uma séria de direitos fundamentais que exigem a garantia de prestação pelo Estado.

A lei federal alemã sobre o direito à informação do consumidor, que há anos está em vigor, parece indicar que a garantia da liberdade de informação se trata de um status positivo dos direitos fundamentais, portanto, de um direito fundamental que deve garantir um benefício estatal, ou, ainda, em todo caso, de um direito fundamental que provavelmente contém uma garantia de defesa e uma garantia de prestação pelo Estado. Uma investigação sobre a sua natureza foi desenvolvida há pouco tempo pela Sra. Lee, uma tarefa difícil, pois o legislador não tinha uma ideia clara da classificação desta lei no direito público ou privado, ou se de status positivo ou negativo. ${ }^{4}$

\section{NOVOS CASOS DE CONFLITO - O ESCÂNDALO DA DIOXINA}

O recente escândalo da dioxina mostrou que uma redefinição ou modificação da lei de informação do consumidor é necessária. Sem dúvida que nunca deveria ser necessário um novo escândalo sobre contaminação de gêneros alimentícios para indicar a omissão do poder legislativo, pois os numerosos escândalos já ocorridos e seus enfrentamentos demonstram a inadequação da regulamentação estatal, em parte a demonstração completa da ausência de legislação estadual de execução.

Inicialmente um breve relato do desenvolvimento da crise da dioxina:

Um fabricante de alimento composto para animais da cidade alemã de Dinklage, no Estado da Baixa Saxônia, ao realizar controles de rotina na empresa detectou elevado nível de dioxina na forragem produzida pela empresa.

\footnotetext{
${ }^{4}$ Ning-Hsiu Lee trata em sua dissertação escrita em Munique "Verbraucherinformationsgesetz aus der Sicht des Rechts auf Zugang zu Verbraucherinformationen - Eine Untersuchung im Vergleich mit den entsprechenden Rechtsnormen in Taiwan", publicada pela editora LIT, de Berlim, em 2011, dos seguintes escândalos ocorridos com gêneros alimentícios e de como os mesmos foram tratados nos tribunais: contaminação de óleo de oliva na Espanha em 1981; glicol nos vinhos alemães e austríacos em 1985; a doença da vaca louca em 1986; carne estragada, especialmente no período de outubro de 2005 a março de 2006; queijo estragado em 2008.
} 
Investigações mostraram que a gordura alimentar contaminada provinha da empresa Harles e Jentzsch, uma fabricante de gordura alimentar da cidade de Uetersen, perto de Hamburgo, que ao lado de gordura alimentar igualmente produz óleo para fins industriais como, por exemplo, processamento de papel. Investigações posteriores revelaram que junto a esta fabricante de gordura alimentar foram misturados ácidos graxos mistos, com elevados níveis de dioxina, que eram utilizados na fabricação de papel, com gordura alimentar vegetal.

Várias empresas de aves, suínos, galinhas poedeiras bem como de produção de leite utilizaram a gordura alimentar contaminada. As empresas suspeitas de terem utilizados os alimentos compostos contaminados foram identificadas e isoladas.

Para se avaliar o dogmatismo dos numerosos novos regramentos e a sua integração ao problema da proteção do direito à informação deve-se observar o projeto de lei apresentado pela Ministra Aigner ${ }^{5}$ em Bruxelas em 04 de março de 2011. A reorganização da proteção dos consumidores faz surgir imediatamente a questão sobre onde nessa lei se sedimenta o direito à informação dos cidadãos. Aparentemente é suficiente o Estado remeter esse direito à reformulação da lei de informação. Adicione a isso uma impressão negativa apesar de todas as tentativas de regulamentação da matéria, pois os cidadãos, segundo essa nova proposição, não possuem aparentemente nenhum direito de reivindicação, senão quando muito o de se aplicar nessas situações o recebimento de determinadas prestações, como, por exemplo, um seguro de responsabilidade civil dos produtores de alimentos ou um endurecimento das disposições penais, ainda que permaneça em aberto a questão se essa infração se constitui um crime ou uma contravenção. Isso será analisado especificamente na sequência.

A seguir as medidas que servem como meio de controle por parte do inspetor do Estado ou privado: (i) a situação das amostras; (ii) inspeções regulares e abrangentes por parte das instituições estatais e privadas; (iii) garantia de transparência do mercado de alimentos; (iv) introdução de um Sistema Nacional de alerta; (v) obrigação de publicação dos relatórios pelas autoridades e publicação resumida dos relatórios trimestrais.

Uma menção também deve ser feita quanto à divisão entre a produção de gorduras para alimentação e a produção de graxas industriais, a fim de se evitar qualquer mistura. Esses diferentes pontos são certamente medidas administrativas boas e seguras, porém elas não reconhecem quais direitos dos cidadãos provenientes do direito fundamental à informação se têm e se podem exercer. Isso será seguramente apartado na regulamentação da nova lei de informação do consumidor. Mas somente se essa nova ordenação do direito à informação conceder uma posição jurídica correspondente a ideia

${ }^{5}$ Ilse Aigner, Ministra Federal alemã para alimentação, agricultura e defesa do consumidor. (N.T.)

DiREITOS FundAMENTAIS E J JUSTIÇA - ANO 6, N 18, P. 13-21, JAN./MAR. 2012 
de direito fundamental, as medidas a serem tomadas pela administração de alimentos e pelo Ministério da agricultura e de proteção ao consumidor podem ter êxito. Aparentemente, no entanto, têm sido negligenciadas as disposições do art. $5^{\circ}$, parte 1 da Lei Fundamental alemã que garante o direito à informação, já abrangidas por acordos internacionais, os quais não podem ser limitados arbitrariamente pelo legislador estadual e nem pelo legislador federal alemães.

Aqui devem ser citadas passagens da exposição de Peter H. Sand ${ }^{6}$ :

$\mathrm{O}$ acesso à informação ambiental e sua repercussão contemporânea para o direito público internacional constitui-se em um campo vasto. A obrigação legal de divulgar informações relacionadas com o meio ambiente já existe em quatro níveis distintos: (i) divulgação para os governos por meio de declarações de impacto ambiental para o planejamento ou licenciamento de projetos específicos, as categorias de indústrias, atividades perigosas para o meio ambiente e para a produção, comercialização ou transporte de "mercadorias perigosas"; (ii) divulgação aos cidadãos sob o "direito de saber" sobre planos para específicos ambientes de trabalho ou para o benefício das comunidades adjacentes das instalações industriais; (iii) divulgação aos consumidores por meio de uma variedade de formas de rotulagem que vão desde advertências de perigo até certificações de conteúdo ou origem; e (iv) divulgação aos investidores como parte da forma contábil e financeira das empresas.

\section{FONTES DE ACESSO GERAL}

Acesso geral é uma fonte de informação que, se ela for tecnicamente precisa e adequada, o público em geral, ou seja, não o individuo ou determinado círculo de pessoas, pode se instruir. ${ }^{7}$ Decisiva é especialmente a verdadeira natureza da prestação da informação. Uma fonte pode ser todo portador imaginável de informações. É insignificante se a fonte se relaciona com assuntos públicos ou privados, ou se a informação contém mais fatos ou opiniões. ${ }^{8}$

A característica de uma fonte de acesso geral não é atingida mesmo que a possibilidade de acesso universal seja afetada por ações estatais. ${ }^{9}$ Por exemplo, a internet é coberta pelo campo de proteção da liberdade de

\footnotetext{
6 Institute of International Law, University of Munich/Germany; formerly Chief, UNEP Environmental Law Unit, and World Bank Legal Adviser for Environmental Affairs. O artigo foi publicado em: Tulane Journal of International and Comparative Law, Bd. 20/2011.

Decisões do Tribunal Constitucional Federal alemão (BVerfGE) 27, 71, 82 e seg; 33, 52, 65; 103, 44, 60. Mais sobre a descrição do conceito "acesso geral" comparar Berger/ Roth/ Scheel, Informationsfreiheitsgesetz Kommentar, 2006, S. 53. F. Hufen, Staatsrecht II Grundrechte, 2007, § 26 § 6. F. Schoch, IFG Kommentar, 2009, Einl. Rn.52. G. Manssen, Staatsrecht II Grundrechte, 2007, § 327. Pieroth/ Schlink, Grundrechte Staatsrecht II, 2009, § 608.

${ }^{8}$ G. Manssen, Staatsrecht II Grundrechte, 2007, Rn. 326. Jarass/ Pieroth, GG Kommentar, 2007, Art. $5^{\circ} \S 15$.

${ }^{9}$ Comparar BVerGE 27, 71, 84. M. Sachs, GG Kommentar, 2009, Art. $5^{\circ} \S 55$.
} 
informação enquanto o conteúdo seja de acesso geral. ${ }^{10}$ "A decisão sobre a acessibilidade e a natureza da amplitude do acesso será de quem pela ordem jurídica dispõe do correspondente poder de determinação" ${ }^{\prime 1}$. De não acesso geral são declarações escritas ou verbais e mensagens dirigidas a um círculo limitado de destinatários bem como registros corporativos ou privados e dados de governo ${ }^{12}$ que ainda não estão destinados à publicação. ${ }^{13}$

"Enquanto a recepção é dependente de sistemas técnicos, os quais a informação dirigida ao público em geral se abre primeiramente de forma individual, o direito de proteção se estende também para a contratação e utilização de tais equipamentos"14. Por exemplo, os meios de comunicação de massa tradicionais, como publicações impressas, rádio, cinema, televisão e serviços de multimídia como a internet. ${ }^{15}$

\section{Informação ao Público em Geral}

Sobre o aspecto do conteúdo a liberdade de informação contém ainda um elemento essencial, a saber, o objetivo de informação ao público em geral. Uma limitação de certos tipos de informações não surge a partir da disposição. ${ }^{16}$

As informações que se encontram com autoridades estatais são em razão de pressupostos gerais, de acesso universal. Exceções existem para os atos de governo e os debates perante os Tribunais. ${ }^{17}$ Uma fonte de informação sob responsabilidade estatal é de acesso geral conforme definido pelo Art. $5^{\circ}$, parte 1 da Lei Fundamental alemã quando ela dispõe que se "determina como de acesso geral em razão de uma afirmação jurídica"18. As restrições de acesso são procedimentos que requerem justificação no direito fundamental de liberdade de informação geral. A negação de acesso à informação é feita pela legislação ordinária em circunstâncias excepcionais que exijam uma justificativa específica. ${ }^{19} \mathrm{~A}$ obrigação de publicação pode provir,

\footnotetext{
${ }^{10}$ Jarass/ Pieroth, GG Kommentar, 2007, Art. $5^{\circ} \S 16$.

${ }^{11}$ BVerfGE 103, 44, 60.

${ }^{12}$ As informações geridas por órgãos estatais não são consideradas "fontes de acesso geral", conforme consta do art. $5^{\circ}$, parte 1 , frase 1 da Lei Fundamental alemã para o período até a entrada em vigor da Lei Federal de liberdade de informação - IFG, em 01 de janeiro de 2006. F. Schoch, IFG Kommentar, 2009, Introdução, § 52.

${ }^{13}$ BVerfGE 66, 116, 137. G. Bauschke, Verbraucherschutz im öffentlichen Recht aus der Sicht des Lebensmittelrechts, 2005, S.103. Jarass/ Pieroth, GG Kommentar, 2007, Art. 5o § 16. J. Ipsen, Staatsrecht IIGrundrechte, 2008, § 431. R. Wendt, in: v. Münch/ Kunig (Hrsg.), GG Kommentar, 2000, Art. $5^{\circ} \S 25$.

${ }_{14}$ BVerfGE 90, 27, 32 .

${ }^{15} \mathrm{G}$. Bauschke, Verbraucherschutz im öffentlichen Recht aus der Sicht des Lebensmittelrechts, 2005, S.103. G. Manssen, Staatsrecht IIGrundrechte, 2007, § 326. M. Sachs, GG Kommentar, 2009, Art. $5^{\circ} \S 54$. J. Ipsen, Staatsrecht II Grundrechte, 2008, § 431.

${ }^{16}$ BVerfGE 90, 27, 32. M. Sachs, GG Kommentar, 2009, Art. $5^{\circ} \S 53$.

${ }^{17}$ BVerfGE 103, 44, 61.

${ }^{18}$ BVerfGE 103, 44, 60. Jarass/ Pieroth, GG Kommentar, 2007, Art. $5^{\circ} \S 16 \mathrm{a}$.

${ }^{19}$ M. Sachs, GG Kommentar, 2009, Art. $5^{\circ} \S 56 a$.
} 
sobretudo, do Princípio da Democracia, mas pode igualmente surgir de uma lei ordinária. Enquanto essa for a situação há uma prerrogativa de acesso à consulta de documentos e informações. ${ }^{20}$

A adequação de fato para informar o público em geral pressupõe que - Estado não tem poderes para decidir sobre a acessibilidade geral de uma fonte de informação por normais legais ou políticas governamentais. ${ }^{21}$ Os limites do art. $5^{\circ}$ parte 2 da Lei Fundamental alemã perderiam o objetivo para a liberdade de informação se o Estado pudesse determinar por meio de suas ações a acessibilidade geral e arbitrariamente pudesse limitar a extensão do direito fundamental. ${ }^{22} \mathrm{O}$ acesso geral à informação está livre da interferência estatal se a referência da informação é subordinada a uma prestação dos interessados como, por exemplo, a cobrança de uma modesta taxa de acesso aos meios de comunicação (Rundfunkgebühr). ${ }^{23}$

\section{Instrução Livre e Direta}

A instrução livre e direta do titular do direito fundamental é protegida pela liberdade de informação. No entanto, esta não apenas contém o fornecimento ativo de informações, mas também o recebimento delas. A possibilidade de o destinatário receber informações não solicitadas se encontra nesse campo de proteção. ${ }^{24}$

Ao lado da liberdade de informação positiva é reconhecida a liberdade de informação negativa. $\mathrm{O}$ art. $5^{\circ}$ parte 1 da Lei Fundamental alemã também protege a liberdade de informação negativa como um direito fundamental, o direito de recusar informações. Sobretudo é constitucionalmente proibido o recebimento compulsório de informações na forma de comandos e ofertas comerciais. Uma intervenção se dá quando ela se reveste de mero aborrecimento ou não oferta qualquer possibilidade de recusa. ${ }^{25} \mathrm{~A}$ liberdade negativa de informações impede inevitavelmente o recebimento forçado de informações por emails, por exemplo. ${ }^{26}$

Violações à liberdade de informação ocorrem quando o acesso à informação não só é definitivamente vedado, mas também está atrasado no tempo, assim como todas as proibições de informações, embargo, recusa de

20 Jarass/ Pieroth, GG Kommentar, 2007, Art. $5^{\circ} \S 16 a$.

${ }^{21}$ M. Sachs, GG Kommentar, 2009, Art. $5^{\circ} \S 57 \mathrm{~b}$. R. Wendt, in: v. Münch/ Kunig (Hrsg.), GG Kommentar $I, 2000$, Art. $5^{\circ} \S 23$.

${ }^{22}$ BVerfGE 27, 71, 84 e seg.

${ }^{23}$ M. Sachs, GG Kommentar, 2009, Art. $5^{\circ} \S 57$.

${ }^{24}$ BVerfGE 27, 71, 82 e seg. F. Hufen, Staatsrecht II Grundrechte, 2007, § 26 § 6. Jarass/ Pieroth, GG Kommentar, 2007, Art. $5^{\circ} \S 17$. Manssen, Staatsrecht II Grundrechte, 2007, § 329. M. Sachs, GG Kommentar, 2009, Art. $5^{\circ} \S 53$.

${ }_{25}$ M. Sachs, GG Kommentar, 2009, Art. $5^{\circ} \S 57$ a

${ }^{26}$ Sobre a dimensão negativa do direito de liberdade de informação comparar Jarass/ Pieroth, GG Kommentar, 2007, Art. $5^{\circ} \S 17$. M. Fikentscher, Die (negative) Informationsfreiheit als Grenze von Werbung und Kunstdarbietung, NJW 1998 Caderno 19, p. 1337 e segs. M. Sachs, GG Kommentar, 2009, Art. 5 § 57a. Pieroth/ Schlink, Grundrechte Staatsrecht II, 2009, § 610. 
entrega, perturbação deliberada, etc. ${ }^{27}$ Também o recolhimento e o registro estatal das fontes de informação, as quais se servem os cidadãos, representam uma violação, mesmo quando eles sejam a única fonte de informação. Com fundamento no art. $5^{\circ}$, parte 1 , frase 1 da Lei Fundamental alemã encontra-se no campo de proteção da norma o direito de escolha entre as múltiplas fontes de informação que estão à disposição. ${ }^{28}$

Os problemas acima mencionados, que se apresentaram particularmente em relação à crise da dioxina, certamente se renovaram de forma semelhante e, em parte, ampliada na crise da bactéria E. coli de 2011. A primeira notícia sobre os casos com a bactéria foi divulgada pelo jornal Welt Online de 24 de maio de $2011^{29}$, que relatou o caso de morte em decorrência da bactéria. Em geral ocorreram nas semanas seguintes perto de cinquenta mortes. Sobre o número de doentes, gravidade das doenças e danos permanentes não houve informações ou elas foram bastante contraditórias. As notícias foram parcialmente retardadas. O Instituto Robert Koch transmitiu uma correspondência de praxe para instituições análogas. O órgão federal alemão de defesa do consumidor também não deu muita atenção ao direito fundamental à informação dos cidadãos, de modo que aqui também foi negligenciada a dimensão positiva de um direito fundamental central.

Essa falha de informações importantes aos cidadãos atingidos destacou claramente a insuficiência da regulamentação legal na Alemanha e levou há pouco a uma proposta de alteração legislativa pelo poder executivo federal.

Os pontos-chave de melhoria são os seguintes:

(i) informar ativamente a opinião pública, especialmente por meio da nova exigência de divulgação obrigatória de todas as violações as normas legais;

(ii) aumentar a participação popular no processamento de pedidos individuais e o rigor dos procedimentos administrativos;

(iii) facilitar a interpretação da lei e aumentar a segurança jurídica para as repartições públicas locais;

(iv) expandir o alcance da lei para todos os produtos de consumo, na acepção da futura lei de segurança do produto. ${ }^{30}$

\footnotetext{
${ }^{27}$ BVerfGE 27, 88, 98 e seg. F. Hufen, Staatsrecht II Grundrechte, 2007, § 26 § 13. Pieroth/ Schlink, Grundrechte Staatsrecht II, 2009, § 628.

${ }^{28}$ BVerfGE 15, 288, 295. F. Hufen, Staatsrecht II Grundrechte, 2007, § $26 \S 13$. Pieroth/ Schlink, Grundrechte Staatsrecht II, 2009, § 628.

${ }_{29}$ Welt online: EHEC-Infektion fordert die ersten Todesopfer vom 24.05.2011, in: http://www.welt.de/gesundheit/article13390941/EHEC-Infektion-fordert-die-ersten-Todesopfer.html, Acessado em 19.07.2011.

${ }^{30}$ http://www.vig-wirkt.de/, acessado em 12.08.2011.
} 
IV A LIBERDADE DE INFORMAÇÃO EM CONFLITO COMO UMA OBSERVAÇÃO FINAL

Mesmo aqui nos casos não tratados de conflito existe é claro o incômodo da oferta por meio de modernização técnica perigosa até então controlada: (i) compra de gordura contaminada com restos de dioxina como alimento para animais; (ii) introdução de ar poluído no interior de aeronaves em razão do uso inadequado de oxigênio; (iii) e, finalmente, o caso do uso do álcool E10, o chamado biocombustível, com base no tratamento de grãos de milho e de canola em prejuízo dos métodos tradicionais de cultivo de plantas e cereais para a nutrição humana.

No caso aqui tratado da dioxina encontra-se uma violação ao direito à saúde, garantido pelo Art. $2^{\circ}$, parte 2 da Lei Fundamental Alemã. O art. 12 da Lei Fundamental que garante o interesse econômico da liberdade de profissão ou do exercício profissional não prevalece. Não há argumento em face da falta de informações ou do direito à segurança da liberdade de informação do cidadão e da prestação automática de informação aos cidadãos conforme dispõe 0 art. $5^{\circ}$, parte 1 , frase 2 da Lei Fundamental. Além disso, o direito à informação pode também ser questionado, porém ele recua em face de um conflito de direitos fundamentais, de modo que se trata aqui de uma ponderação de direitos fundamentais.

O direito à informação tem, neste ponto, uma dupla função na medida em que ele não é apenas dirigido em face do Estado, mas pode como garantia institucional produzir efeito em face de pessoas privadas como pessoas naturais ou pessoas jurídicas. Na condição de um direito subjetivo e como uma construção objetiva ou instituição pode ter efeito sobre omissões, mas também sobre a natureza de um direito a uma prestação positiva. Esse direito pertence, portanto, ao status negativo como também ao status positivo.

Deve-se notar criticamente que os Princípios que foram estabelecidos pela Ministra da Agricultura alemã não garantem, aparentemente, em suas origens nenhum direito à informação; eles, de fato, tornam o direito à informação superficial ou desnecessário, tanto na forma negativa quanto na forma positiva. Não se pode conhecer ou reconhecer no cumprimento dos dez pontos a realização do direito à informação, pois muito mais se vê a tentativa de tais direitos serem simplesmente excluídos por meio de um determinado procedimento estatal. Se se pode também se subordinar à boa vontade do Estado e das repartições públicas, deve-se ressaltar, no entanto, que o direito à informação não pode ser excluído.

A demanda por uma nova e aperfeiçoada lei sobre liberdade de informação está justificada; ela não deve se restringir apenas aos consumidores, aos típicos bens de consumo das pessoas, mas conceder o acesso onde a realização dos direitos fundamentais por meio das mudanças da sociedade é ameaçada. Deveria ser a rigor uma lei de informação ao cidadão. 
Enquanto isso o Governo Federal alemão se decidiu por uma nova lei e iniciou o processo de aprovação parlamentar, o que por certo irá melhorar claramente a insuficiente situação atual. Simultaneamente o Ministério Federal alemão para Alimentação, Agricultura e Defesa do Consumidor abriu um portal na internet ${ }^{31}$ que, devido ao grande número de acessos pela opinião pública alemã, entrou em colapso algumas horas depois ou ficou muito lento em razão da sobrecarga. Nada poderia melhor provar a até então falha na concessão de informações necessárias como a grande quantidade de demanda informacional, o que levou quase à ineficiência da prestação de informações.

\section{REFERÊNCIAS}

BAUSCHKE, Gabriele. Verbraucherschutz im öffentlichen Recht aus der Sicht des Lebensmittelrechts. Köln: Carl Heymanns, 2005.

BERGER, Sven; ROTH, Jürgen; SCHEEL, Christopher. Informationsfreiheitsgesetz Kommentar. Köln: Carl Heymanns, 2006.

FIKENTSCHER, Wolfgang; MÖLLERS, Thomas M. Die (negative) Informationsfreiheit als Grenze von Werbung und Kunstdarbietung. Neue Juristische Wochenschrift. V. 19, 1998.

HUFEN, Friedhelm. Staatsrecht II: Grundrechte. München: C.H. Beck, 2007.

IPSEN, Jörn. Staatsrecht II Grundrechte. München: Franz Vahlen, 2008.

JARASS, Hans D.; PIEROTH, Bodo. Grundgesetz für die Bundesrepublik Deutschland Kommentar. München: C.H. Beck, 2007.

LEE, Ning-Hsiu. Verbraucherinformationsgesetz aus der Sicht des Rechts auf Zugang zu Verbraucherinformationen - Eine Untersuchung im Vergleich mit den entsprechenden Rechtsnormen in Taiwan. Berlim: LIT, 2011.

MANSSEN, Gerrit. Staatsrecht II Grundrechte. München: C.H. Beck, 2007.

PIEROTH, Bodo; SCHLINK, Bernhard. Grundrechte Staatsrecht II. Heidelberg: C.F. Müller, 2009.

SACHS, Michael. Grundgesetz. Kommentar. München: C.H. Beck, 2009.

SAND, Peter $\mathrm{H}$. The Right To Know: Freedom of Environmental Information in Comparative and International Law. Tulane Journal of International and Comparative Law, $n^{\circ} 20,2011$.

SCHOCH, Friedrich. Informationsfreiheitsgesetz (IFG). München: C.H. Beck, 2009.

WENDT, Rudolf. in: v. MÜNCH, Ingo; KUNIG, Philip. (Eds.). Grundgesetz. Kommentar. München: C.H. Beck, 2000.

\footnotetext{
${ }^{31}$ O portal lebensmittelklarheit.de dá uma série de exemplos de esclarecimento de informações sem satisfazer um pouco o desejo pragmático dos critérios em três cores para os produtos alimentícios.
}

DiREITOS FUNDAMENTAIS E E JUSTIÇA - ANO 6, N' 18, P. 13-21, JAN./MAR. 2012 